Review

\title{
Tumor Heterogenity in Gastro-Entero-Pancreatic Neuroendocrine Neoplasia
}

\author{
Ludovica Magi $^{1,2}$, Maria Rinzivillo ${ }^{2}$ and Francesco Panzuto ${ }^{2, *(1)}$ \\ 1 SAIMLAL Department (Human Anatomy, Histology, Forensic Medicine and Orthopedics), \\ Sapienza University of Rome, 00185 Rome, Italy; ludovica.magi@uniroma1.it \\ 2 Digestive Disease Unit, Sant'Andrea University Hospital-ENETS Center of Excellence of Via di Grottarossa, \\ 1035, 00189 Rome, Italy; mrinzivillo@ospedalesantandrea.it \\ * Correspondence: fpanzuto@ospedalesantandrea.it
}

check for updates

Citation: Magi, L.; Rinzivillo, M.; Panzuto, F. Tumor Heterogenity in Gastro-Entero-Pancreatic

Neuroendocrine Neoplasia.

Endocrines 2021, 2, 28-36. https:// doi.org/10.3390/endocrines2010003

Received: 19 December 2020

Accepted: 21 January 2021

Published: 25 January 2021

Publisher's Note: MDPI stays neutral with regard to jurisdictional claims in published maps and institutional affiliations.

Copyright: (c) 2021 by the authors. Licensee MDPI, Basel, Switzerland. This article is an open access article distributed under the terms and conditions of the Creative Commons Attribution (CC BY) license (https:// creativecommons.org/licenses/by/ $4.0 /)$.

\begin{abstract}
Owing to the rarity and the biological and clinical heterogeneity of gastroenteropancreatic neuroendocrine neoplasia (GEP NEN), the management of these patients may be challenging for physicians. This review highlights the specific features of GEP NEN with particular attention on the role of Ki67 heterogeneity, the potential prognostic role of novel radiological techniques, and the clinical usefulness of functional imaging, including 68Ga-DOTA-SST PET/CT and 18F-FDG PET/CT. Understanding these specific features may help to plan proper and tailored follow-up programs and therapeutic approaches.
\end{abstract}

Keywords: neuroendocrine tumors; Ki67; carcinoids; somatostatin analogs; radiomic; positron emission tomography

\section{Introduction}

Neuroendocrine neoplasia (NEN) is a heterogeneous group of diseases arising from the diffuse neuroendocrine system, a wide spectrum of cells distributed throughout the body able to secrete a variety of hormones and biogenic amines [1]. Although considered relatively rare, they are increasing over time, accounting for about $0.5 \%$ of new malignancies diagnosis [2]. The improved use of radiology and better recognition of neuroendocrine histology may explain this trend [3].

Gastroenteropancreatic (GEP) NEN, including NEN of the gastrointestinal tract (GI $\mathrm{NEN}$ ) and the pancreas (pNEN), are extremely heterogenous in term of both clinical and pathological features.

Even if considered as a long-term indolent disease, the growth pattern could be either very low progressive or rapidly aggressive depending on the tumor site, grading and staging. Ki67 is considered the most important prognostic factor and the strongest predictor for poor clinical outcome, driving clinicians to plan their therapeutic choice [4].

Tumor heterogeneity, especially inter-tumor heterogeneity, is well known to be an intrinsic hallmark in this neoplasia, starting with the tumor's location to its clinical and functional aspects. Furthermore, the different (epi)genetic and molecular pathways involved in NEN lead to an extreme variability in tumor biology as it follows from a different ability to metastasize along with the diverse pattern of metastases.

The emerging concept of intra-tumor heterogeneity in NEN is otherwise less explored.

This refers in particular to the heterogeneity, within the same tumor, of the proliferative activity and functional aspects in terms of somatostatin receptor (SSTR) expression.

Ki-67 heterogeneity is well-known, depending on biopsy size as well as by comparing $\mathrm{Ki}-67$ in the primary tumor with that in metastatic recurrences [5]. Furthermore, the proliferative activity might change over time, advising the need of repeating histological evaluation to re-assess proliferative activity during the course of the disease in selected cases [4]. 
A hallmark of GEP NEN is the expression of somatostatin receptors (SSTR) on the tumor cell surface, a feature that may be used for both diagnostic and therapeutic tool [6]. Notably, SSTR expression intensity may vary among different tumor lesions in the same patients. Furthermore, a heterogenous glycometabolic activity has been observed in some patients with NEN, owing to the possibility of different radiotracer avidity showed by ${ }_{18}$ F-FDG PET/CT. Thus, a combined use of 68Ga-DOTA-TATE PET/CT and 18F-FDG PET/CT has been suggested to combine the potential diagnostic accuracy of these tools [7].

Over the last few years, radiomics has played a significant role in the diagnostic work-up of NEN by identifying textural parameters potentially able to reflect tumor cell heterogeneity and correlating with histological grading [8].

As far as tumor treatment is concerned, surgery remains the sole curative option in localized GEP NEN; however, in advanced disease, a broad therapeutic scenario is available, including somatostatin analogs (octreotide and lanreotide), peptide receptor radionuclide therapy (PRRT), targeted therapies (everolimus and sunitinib), and systemic chemotherapy [9]. Given the complexity of these neoplasms, a multidisciplinary management is recommended for effective care of patients with this uncommon kind of malignancy [10].

The importance of tumor heterogeneity is notably emphasized in these neoplasms, but reviews on this topic are scarce. However, this heterogeneity, especially in the same disease, is a crucial aid for clinicians to better manage patients with this uncommon kind of neoplasm. Thus, in this review, we explore different aspects of tumor heterogeneity in GEP NEN from a clinical point of view, with the aim to better understand the complexity of these neoplasms.

\section{Location and Clinical Presentation}

According to the embryonic divisions of the digestive tract, GEP NEN were at first divided in the foregut, (bronchopulmonary, stomach, duodenum, biliary, and pancreas), midgut (jejunum, ileum, appendix, and proximal colon), and hindgut (distal colon and rectum) [11]. This classification provides the first source of heterogeneity, in which the organ/tissue of origin already imprints a distinct set of influencing features defining the precise nature of the tumor.

The small intestine and the rectum are the most common primary NEN sites in the digestive tract accounting for $30.8 \%$ and $26.3 \%$, respectively [12]. GEP NENs are clinically divided in functional (30\%) and non-functional ( $70 \%)$ according to their ability to secrete hormones or peptides providing a wide variety of symptoms related to a clinical syndrome [3]. In patients with a functional GEP NEN, a correct clinical work-up is crucial and must be considered in therapeutic strategy. Above all the possible syndromes related to these neoplasms, the most frequent is the carcinoid syndrome characterized by release of serotonin determining diarrhea, cutaneous flushing and in $20 \%$ of cases a carcinoid heart disease with cardiac valve dysfunction. This syndrome is associated with NEN of the small intestine, especially when liver metastases occur [13,14]. Most pNENs are hormonally silent but, in a small rate of patients, a broad spectrum of clinical syndromes may be present providing a heterogenous clinical scenario ranging from severe peptic ulcer-disease in gastrinomas to grave hypoglycemia in insulinomas. However, it is important to remark that up to $90 \%$ of patients with pNEN are hormonally silent with an increasing rate of small and asymptomatic pNEN incidentally diagnosed by imaging. Non-functioning GEP NEN have generally a silent course and are incidentally diagnosed during imaging, endoscopies or surgery ruled out for other reason. If symptoms are present, such as abdominal pain or discomfort, they are usually non-specific leading to a delayed diagnosis.

In some cases, an acute onset may occur (e.g., intestinal obstruction), requiring urgent surgery and hospitalization.

Furthermore, the heterogenous clinical presentation of GEP NEN it is also affected by the possibility, in less than $1 \%$ of patients, that the tumor arises as part of hereditary familial syndromes, including multiple endocrine neoplasia type 1 (MEN-1), von Hippel Lindau (VHL) syndrome, tuberous sclerosis, and neurofibromatosis type 1 [15]. A familial 
syndrome may be suspected particularly in presence of pNEN associated with a family history of others benign or malign neoplasms such as pheochromocytoma, hamartomas, neurofibromas, NEN of the pituitary or the parathyroids gland. However, in most cases, GEP NENs are sporadic without any familial link.

\section{Pathology, Staging and Prognosis}

Given their rarity and heterogenous pathological aspects, the diagnosis of this neoplasm is still a challenge for the pathologist. A broad spectrum of immunohistochemical markers may be present on the cell's surface; however, synaptophysin and chromogranin A ( $\mathrm{CgA})$ are usually mainly expressed in well differentiated GEP NENs, whereas poorly differentiated tumors acquire neuron-specific enolase (NSE) expression loosing CgA expression. Furthermore, other immunohistochemical markers such as insulin gene enhancer protein 1 (ISL1), caudal type homeobox 2 (CDX2) and thyroid transcription factor 1 (TTF1), can be useful to identify primary sites in metastatic well differentiated NEN of unknown origin [1]. After characterization, the next step consists of the assessment of tumor grade or proliferative activity, determinate by number of mitosis and/or Ki-67 index evaluated at immunohistochemistry. Furthermore, tumor cells may maintain characteristics of the "normal cells", in case of well differentiated NEN, or become poorly differentiated with extensive necrosis areas. As far as tumor grade is concerned, the heterogenous tumor biology of these neoplasia, makes it difficult to provide a grading system which satisfy all categories. In 2010, The World health Organization (WHO) distinguished into three categories based on proliferative activity and cell's differentiation: NEN G1 (Ki67 $\leq 2 \%)$ or G2 (Ki67: 3-20\%), and poorly differentiated neuroendocrine carcinoma (NEC) G3 with a Ki67 $>20 \%$. The new WHO classification updated the cut-off for well differentiated G1-G2 pNEN from $2 \%$ to $3 \%$ and introduced a new category of high grade well differentiated pNEN (NEN G3 = well differentiated tumors with Ki67 > 20\%) which consists of a separate entity compared with NEC G3 [16-18]. This last group includes tumors which are further subclassified into small cell and large cell types. Indeed, the Ki67 level of $>55 \%$ has been further proposed to identify those diseases with a higher response to chemotherapy and worse prognosis, compared to those with a lower proliferative activity $(<55 \%)[19,20]$. Correct assessment of tumor grade is crucial as Ki-67 has been well demonstrated to be the most important prognostic factor and the strongest predictor for poor clinical outcome in GEP NEN [21,22]. Furthermore, Ki-67 is determinant in planning therapeutic management in these patients. However, intra-tumor heterogeneity is well recognized in these neoplasms, either for primary site or metastatic recurrences, especially for $\mathrm{G} 2$ grading $[5,23]$. Tumor grade discrepancies are even present between primary and metastases and between different metastatic sites $[24,25]$. Thus, random sampling biopsy, the usual diagnostic tool, may be not confident with the real degree of tumor proliferative activity. Furthermore, GEP NENs often have a long disease course and proliferative activity might change over time in about $65 \%$ of patients, hence, a histological evaluation to re-assess proliferative activity should be performed in selected cases with rapidly progressive disease, particularly in those of pancreatic origin [4].

Compared to other cancers, GEP NENs are usually considered less aggressive, with a potentially indolent clinical course. However, prognosis is very heterogenous depending on several factors including site of origin, grading, staging and tumor burden. In these patients with advanced disease, combining different risk factors may provide a prognostic tool able to better predict clinical outcome, compared with a given single risk factor [26-28].

\section{Imaging Investigations}

Several modalities of conventional imaging are available for detecting and staging GEP NEN, including ultrasonography (US), computed tomography (CT) or magnetic resonance imaging (MRI). Diagnosis of gastric, duodenal or rectal NEN are usually incidental occurring during endoscopic procedures (esofagogastroduodenoscopy, colonoscopy). In some cases, additional endoscopic ultrasound (EUS) is crucial for asses the degree of 
tumor invasion and presence of lymph nodes metastases. EUS is also widely used for tumor assessment in pNEN either to evaluate disease extension or to provide histological specimen through random sampling biopsy [29]. Given the emerging evidence of heterogeneity of proliferative activity as described earlier, one of the novel aims of the radiological examinations is to find association between "qualitative" and "quantitative" information, extracted from pre-existing images, able to correlate with tumor heterogeneity. This strand refers to "Radiomics" or Texture Analysis (MRI or CT Texture Analysisis), an emerging area of research which has provided promising results on prognosis and therapy response assessment in oncologic practice [30]. To date, major research domains of Radiomics in NEN has been the non-invasive determination of tumor grade, in order to quantify tumor heterogeneity [31-33]. However, accurate prediction of tumor grade in GEP NEN is still limited. In a recent experience from our group, it was showed that some textural parameters such as Kurtosis and Entropy were associated with a poorest prognosis at CT Texture evaluation [34]. In that study, it was also demonstrated that $\mathrm{CT}$ texture features, such as Mean and Skewness, were significantly different between pNEN and GI NEN, a figure that may be related to the different biological features of these two kinds of NEN which results in a usually more unfavorable clinical outcome of pNEN, compared with GI NEN [35]. One of the hallmarks of NEN is the expression of SSTR on a cell's surface, a feature that may be used for both diagnostic and therapeutic tool. Overall, almost $90 \%$ of well differentiated GEP NENs present a positive finding at somatostatin receptors imaging (SRI) and its impact on clinical outcome has been widely demonstrated affecting both staging and therapeutic choice [36]. Indeed, the presence of SSTR is crucial for the management of NEN, particularly when considering treatment with somatostatin analogues (SSA) and to select patients to be treated with peptide receptor radionuclide therapy (PRRT). SRI imaging has been evolved in last years, and those with 68Ga-labelled peptides (68Ga-DOTA-SST PET/CT) are currently considered the gold standard in the diagnosis and management of well differentiated neuroendocrine tumors. However, poorly differentiated G3 NEN or NEN with a high mitotic index, usually loose this characteristic showing an increased glucose metabolism similar to aggressive forms such as adenocarcinoma or undifferentiated disease. Indeed, in the last few years, the role of 18F-FDG PET/CT in these neoplasms has emerged as an important tool to define tumor aggressiveness and give relevant prognostic information especially in the management of G3 NEN [7,37]. In fact, it has been well demonstrated that 18F-FDG PET/CT has a high diagnostic accuracy to identify progression of disease with unfavorable clinical outcomes in patients with advanced GEP NEN [38]. In addition, its recently emerging the potential role of 18F-FDG PET/CT in predicting response to PRRT in advanced NEN [39-41]. According to the heterogenous biology of these neoplasms, the application of dual tracer functional imaging has shown that areas of different uptake among the same lesions may be present in pNEN [42]. Furthermore, a correspondence between predominant tumor uptake (SRI or FDG) and tumor grade on histology was demonstrated confirming that 68Ga-DOTA-SST PET/CT is superior to 18F-FDG PET/CT imaging in well differentiated NEN [43]. A correlation between $\mathrm{SUV}_{\max }$ and proliferative activity has also been explored however with heterogenous results. Partelli et al., reported that the median $\mathrm{SUV}_{\max }$ value varied between 31.5 and 53.5 in G1-G2 pancreatic NEN at 68Ga-DOTA-SST PET/CT, whereas it was 16.5 in the G3 subgroup. Finally, a prognostic role of $\mathrm{SUV}_{\max }$ was proposed by Ambrosini et al., who showed that a SUV max value $>38$ at 68Ga-DOTA-SST PET /CT correlated with better prognosis compared with those with a lower $\mathrm{SUV}_{\max }$ value, in a series of G1-G2 pancreatic NEN $[36,42]$.

Thus, a combined use of both modalities may play a role to better understand tumor biology in selected patients with heterogenous uptake avidity, rapidly progressive disease or discrepancy between radiological assessment and clinical evaluation [7]. 


\section{Treatment Options and Management}

Treatment of GEP NEN is affected by several features including site, staging, somatostatin receptor's expression and tumor grade, but the latter is probably the most employed in clinical practice. To date surgery is considered the only curative option and it is recommended in G1 or G2 tumors, even in the presence of locoregional disease [9]. Conversely, selected cases with limited disease may be managed by a non-invasive approach by endoscopic follow-up or clinical observation, depending on the primary tumor site [44].

The role of the endoscopist in the management of gastrointestinal NEN has emerged over recent years, in particular for small gastric or rectal NEN with no risk of lymphovascular invasion. The two main endoscopic techniques used in this setting are the endoscopic mucosal resection (EMR) and the endoscopic submucosal dissection (ESD), however the latter is preferred to better achieve complete resection.

In advanced disease of well differentiated G1 or G2 GEP NEN and in the presence of SSTR expression, somatostatin analogues (SSA) are commonly employed as first line systemic therapy. After the failure of SSA analogues, a broad scenario of therapeutic options is available including loco-regional therapies, systematic therapies, chemotherapy, and novel agents [45]. Loco-regional therapies (e.g., embolization, radiofrequency ablation or microwave destruction) or cytoreductive surgery should be indicated either in functional tumors to reduce symptoms related to a syndrome (e.g., carcinoid syndrome) or, in non-functional NEN, when disease is limited to the liver $[9,46,47]$. In recent years, the therapeutic scenario of systematic therapies for metastatic GEP NEN has expanded considerably as showed in Table 1 [48-53]. Finally, in poorly differentiated NEC G3, chemotherapy remains the treatment of choice (platinum based regimen), but it may be considered also in well differentiated NEN in case of rapidly progressive disease and/or after failure of other therapies, or if SSTR imaging is negative (e.g., capecitabine/temozolomide) [9].

Table 1. Approved medical treatment for advanced G1-G2 GEP NEN.

\begin{tabular}{|c|c|c|c|c|}
\hline Study & $\begin{array}{c}\text { Treatment } \\
\text { Investigated }\end{array}$ & $\begin{array}{l}\text { Population } \\
\text { Enrolled }\end{array}$ & Median PFS & ORR \\
\hline PROMID [48] & $\begin{array}{l}\text { Octreoride LAR } 30 \mathrm{mg} \\
\text { every } 4 \text { weeks }\end{array}$ & Naïve midgut NEN & $14.3 \mathrm{mo}$ & $2 \%$ \\
\hline $\begin{array}{l}\text { CLARINET } \\
{[49,50]}\end{array}$ & $\begin{array}{l}\text { Lanreotide } 120 \mathrm{mg} \\
\text { every } 4 \text { weeks }\end{array}$ & $\begin{array}{l}\text { Advanced SSTR }{ }^{+} \\
\text {GEP NEN }\end{array}$ & $32.8 \mathrm{mo}$ & NR \\
\hline RADIANT 3 [51] & Everolimus $10 \mathrm{mg}$ & Progressive pNEN & $11 \mathrm{mo}$ & $5 \%$ \\
\hline RADIANT 4 [52] & Everolimus $10 \mathrm{mg}$ & $\begin{array}{c}\text { Progressive } \\
\text { nonfunctional lung } \\
\text { or GI NEN }\end{array}$ & $11 \mathrm{mo}$ & $2 \%$ \\
\hline NETTER 1 [53] & ${ }^{177} \mathrm{Lu}-\mathrm{Lu}$ DOTATE & $\begin{array}{l}\text { Progressive SSTR }{ }^{+} \\
\text {midgut NEN }\end{array}$ & NR & $18 \%$ \\
\hline
\end{tabular}

Abbreviations: +, positive; 177Lu-DOTATATE, lutetium-177 dotatate; GEP NEN, gastroenteropancreatic neuroendocrine neoplasia; GI, gastrointestinal; LAR, long-acting repeatable; NEN, neuroendocrine neoplasia; NR, not reached; ORR, overall response rate; PFS, progression-free survival; pNEN, pancreatic neuroendocrine neoplasia; SSTR, somatostatin receptor.

In functional tumors, symptoms related to a syndrome, may be controlled either by surgery, or loco-regional therapies or finally by medical treatment (e.g., diazoxide for insulinoma, anti-secretive and anti-diarrheal drugs in Zollinger-Ellison syndrome). SSA are used for both control carcinoid syndrome and tumor growth.

Thus, the heterogeneous clinical scenario of these neoplasms leads to a broad spectrum of possible therapeutic options and medical figures involved the management of patients with this neoplasma.

To date, a clear treatment algorithm in progressive disease is still lacking. Furthermore, the heterogenous biology of GEP NEN in terms of both proliferative activity and SSTR expression, as described earlier, makes it difficult to choose best therapeutic approach. 
Thus, early referral to NEN-dedicated centers may have important implications in reduce delayed diagnosis and give the possibility of a multidisciplinary therapeutic approach in a dedicated team improving patient's clinical outcome [10].

\section{Conclusions}

GEP neuroendocrine neoplasia are considered a heterogeneous disease for both clinical and biological behavior, especially for patients with multiple metastases. This review explores different layers of heterogeneity in GEP NEN and highlights new advances in imaging in order to quantify tumor heterogeneity and, moreover, the necessity of a multidisciplinary approach to manage these complex and rare neoplasms, Figure 1.

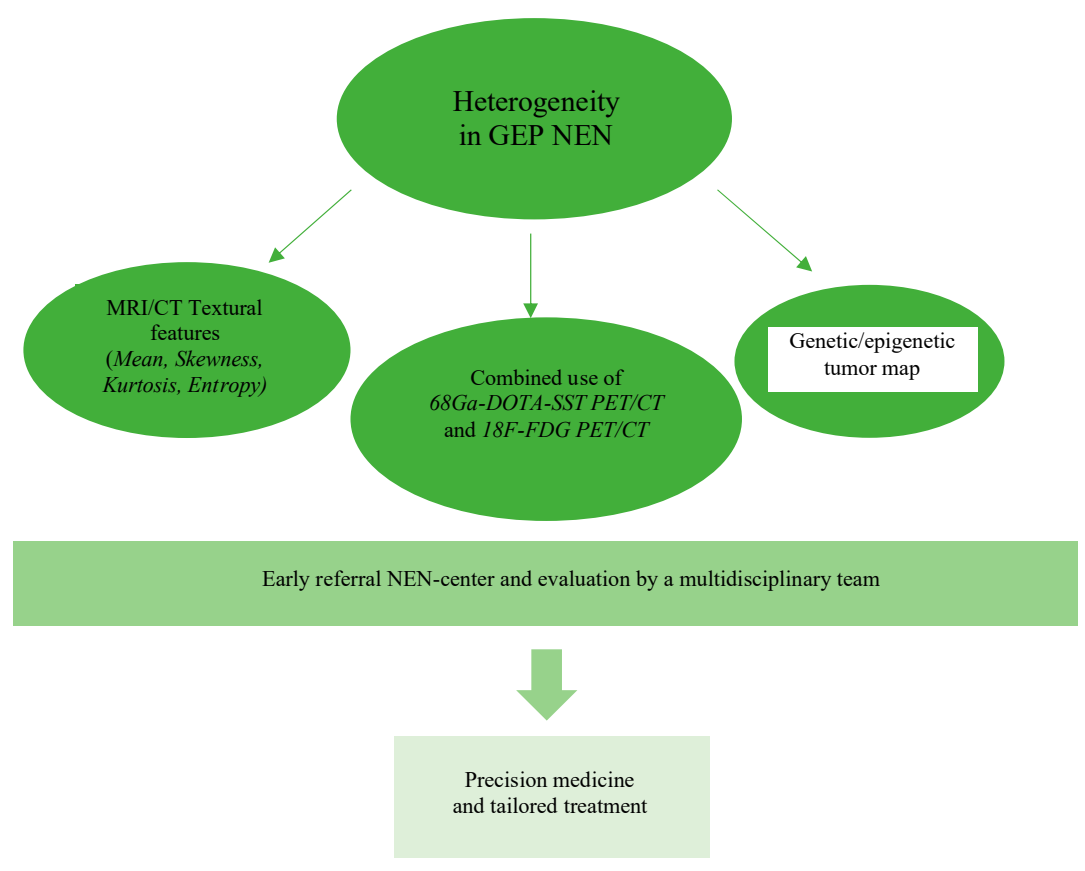

Abbreviations: GEP Gastroenteropancreatic; NEN neuroendocrine neoplasia; MRI magnetic resonance imaging; CT computed tomography; Ga Gallium; SST somatostatin; DOTA 1,4,7,10-Tetraazacyclododecane-1,4,7,10-tetraacetic acid; PET Positron emission tomography; F Fluor; FDG fluorodeoxyglucose.

Figure 1. Future Directions in GEP NEN.

We particularly focused on the heterogeneity of proliferative activity as its crucial role to assess prognosis and planning therapeutic options. As a consequence, the recent tendency is to use conventional or functional imaging in order to provide a surrogate for tumor biology in terms of both proliferative activity and somatostatin receptor expression.

Understanding the heterogeneity of these neoplasms may provide useful information for a tailored follow-up program and a personalized therapeutic approach in patients with GEP NEN.

Funding: This research received no external founding.

Institutional Review Board Statement: Not applicable.

Informed Consent Statement: Not applicable.

Conflicts of Interest: The authors declare no conflict of interest. 


\section{References}

1. Cives, M.; Strosberg, J.R. Gastroenteropancreatic Neuroendocrine Tumors. CA Cancer J. Clin. 2018, 68, 471-487. [CrossRef]

2. Dasari, A.; Shen, C.; Halperin, D.; Zhao, B.; Zhou, S.; Xu, Y.; Shih, T.; Yao, J.C. Trends in the Incidence, Prevalence, and Survival Outcomes in Patients with Neuroendocrine Tumors in the United States. JAMA Oncol. 2017, 3, 1335-1342. [CrossRef]

3. Kulke, M.H.; Shah, M.H.; Benson, A.B., 3rd; Bergsland, E.; Berlin, J.D.; Blaszkowsky, L.S.; Emerson, L.; Engstrom, P.F.; Fanta, P.; Giordano, T.; et al. Neuroendocrine Tumors, Version 1.2015. J. Natl. Compr. Cancer Netw. 2015, 13, 78-108. [CrossRef] [PubMed]

4. Panzuto, F.; Cicchese, N.; Partelli, S.; Rinzivillo, M.; Capurso, G.; Merola, E.; Manzoni, M.; Pucci, E.; Iannicelli, E.; Pilozzi, E.; et al. Impact of Ki67 re-assessment at time of disease progression in patients with pancreatic neuroendocrine neoplasms. PLoS ONE 2017, 12, e0179445. [CrossRef] [PubMed]

5. Grillo, F.; Valle, L.; Ferone, D.; Albertelli, M.; Brisigotti, M.P.; Cittadini, G.; Vanoli, A.; Fiocca, R.; Mastracci, L. KI-67 heterogeneity in well differentiated gastro-entero-pancreatic neuroendocrine tumors: When is biopsy reliable for grade assessment? Endocrine 2017, 57, 494-502. [CrossRef] [PubMed]

6. Sundin, A.; Arnold, R.; Baudin, E.; Cwikla, J.B.; Eriksson, B.; Fanti, S.; Fazio, N.; Giammarile, F.; Hicks, R.J.; Kjaer, A.; et al. ENETS Consensus Guidelines for the Standards of Care in Neuroendocrine Tumors: Radiological, Nuclear Medicine and Hybrid Imaging. Neuroendocrinology 2017, 105, 212-244. [CrossRef]

7. Carideo, L.; Prosperi, D.; Panzuto, F.; Magi, L.; Pratesi, M.S.; Rinzivillo, M.; Annibale, B.; Signore, A. Role of Combined [ ${ }^{68}$ Ga]GaDOTA-SST Analogues and $\left[{ }^{18}\right.$ F]FDG PET/CT in the Management of GEP-NENs: A Systematic Review. J. Clin. Med. $2019,8,1032$. [CrossRef]

8. Weber, M.; Kessler, L.; Schaarschmidt, B.; Fendler, W.P.; Lahner, H.; Antoch, G.; Umutlu, L.; Herrmann, K.; Rischpler, C. Treatment-related changes in neuroendocrine tumors as assessed by textural features derived from ${ }^{68}$ Ga-DOTATOC PET/MRI with simultaneous acquisition of apparent diffusion coefficient. BMC Cancer 2020, 20, 1-12. [CrossRef]

9. Pavel, M.; Otoole, D.; Da Costa, F.B.; Capdevila, J.; Gross, D.J.; Kianmanesh, R.; Krenning, E.P.; Knigge, U.; Salazar, R.; Pape, U.-F.; et al. ENETS Consensus Guidelines Update for the Management of Distant Metastatic Disease of Intestinal, Pancreatic, Bronchial Neuroendocrine Neoplasms (NEN) and NEN of Unknown Primary Site. Neuroendocrinology 2016, 103, 172-185. [CrossRef]

10. Magi, L.; Mazzuca, F.; Rinzivillo, M.; Arrivi, G.; Pilozzi, E.; Prosperi, D.; Iannicelli, E.; Mercantini, P.; Rossi, M.; Pizzichini, P.; et al. Multidisciplinary Management of Neuroendocrine Neoplasia: A Real-World Experience from a Referral Center. J. Clin. Med. 2019, 8, 910. [CrossRef]

11. Williams, E. The Classification of Carcinoid Tumours. Lancet 1963, 281, 238-239. [CrossRef]

12. Yao, J.; Hassan, M.M.; Phan, A.T.; Dagohoy, C.G.; Leary, C.C.; Mares, J.E.; Abdalla, E.K.; Fleming, J.B.; Vauthey, J.-N.; Rashid, A.; et al. One Hundred Years After "Carcinoid": Epidemiology of and Prognostic Factors for Neuroendocrine Tumors in 35,825 Cases in the United States. J. Clin. Oncol. 2008, 26, 3063-3072. [CrossRef] [PubMed]

13. Ray, D.; Williams, G. Pathophysiological causes and clinical significance of flushing. Br. J. Hosp. Med. 1993, 50, 594-598. [PubMed]

14. Grozinsky-Glasberg, S.; Grossman, A.B.; Gross, D.J. Carcinoid Heart Disease: From Pathophysiology to Treatment-'Something in the Way It Moves'. Neuroendocrinology 2015, 101, 263-273. [CrossRef] [PubMed]

15. Taal, B.; Visser, O. Epidemiology of Neuroendocrine Tumours. Neuroendocrinology 2004, 80, 3-7. [CrossRef] [PubMed]

16. Rindi, G.; Arnold, R. Nomenclature and classification of neuroendocrine neoplasms of the digestive system. In World Health Organization Classification of Tumours of the Digestive System; Bosman, F., Carneiro, F., Hruban, R., Theise, N., Eds.; IARC Press: Lyon, France, 2010; pp. 13-14.

17. Rindi, G.; Klersy, C.; Albarello, L.; Baudin, E.; Bianchi, A.; Buchler, M.W.; Caplin, M.J.; Couvelard, A.M.; Cros, J.M.; de Herder, W.W.; et al. Competitive testing of the WHO 2010 versus the WHO 2017 grading of pancreatic neuroendocrine neoplasms: Data from a large international cohort study. Neuroendocrinology 2018, 107, 375-386. [CrossRef]

18. Nagtegaal, I.D.; Odze, R.D.; Klimstra, D.; Paradis, V.; Rugge, M.; Schirmacher, P.; Washington, M.K.; Carneiro, F.; Cree, I.A. the WHO Classification of Tumours Editorial Board. The 2019 WHO classification of tumours of the digestive system. Histopathology 2020, 76, 182-188. [CrossRef]

19. Sorbye, H.; Welin, S.; Langer, S.W.; Vestermark, L.W.; Holt, N.; Osterlund, P.; Dueland, S.; Hofsli, E.; Guren, M.G.; Ohrling, K.; et al. Predictive and prognostic factors for treatment and survival in 305 patients with advanced gastrointestinal neuroendocrine carcinoma (WHO G3): The NORDIC NEC study. Ann. Oncol. 2012, 24, 152-160. [CrossRef]

20. Garciacarbonero, R.; Sorbye, H.; Baudin, E.; Raymond, E.; Wiedenmann, B.; Niederle, B.; Sedlackova, E.; Toumpanakis, C.; Anlauf, M.; Cwikla, J.B.; et al. ENETS Consensus Guidelines for High-Grade Gastroenteropancreatic Neuroendocrine Tumors and Neuroendocrine Carcinomas. Neuroendocrinology 2016, 103, 186-194. [CrossRef]

21. Panzuto, F.; Boninsegna, L.; Fazio, N.; Campana, D.; Brizzi, M.P.; Capurso, G.; Scarpa, A.; De Braud, F.; Dogliotti, L.; Tomassetti, P.; et al. Metastatic and Locally Advanced Pancreatic Endocrine Carcinomas: Analysis of Factors Associated with Disease Progression. J. Clin. Oncol. 2011, 29, 2372-2377. [CrossRef]

22. Panzuto, F.; Campana, D.; Fazio, N.; Brizzi, M.P.; Boninsegna, L.; Nori, F.; Di Meglio, G.; Capurso, G.; Scarpa, A.; Dogliotti, L.; et al. Risk Factors for Disease Progression in Advanced Jejunoileal Neuroendocrine Tumors. Neuroendocrinology 2012, 96, 32-40. [CrossRef] [PubMed]

23. Yang, Z.; Tang, L.H.; Klimstra, D.S. Effect of Tumor Heterogeneity on the Assessment of Ki67 Labeling Index in Well-differentiated Neuroendocrine Tumors Metastatic to the Liver. Am. J. Surg. Pathol. 2011, 35, 853-860. [CrossRef] [PubMed] 
24. Grillo, F.; Albertelli, M.; Brisigotti, M.P.; Borra, T.; Boschetti, M.; Fiocca, R.; Ferone, D.; Mastracci, L. Grade Increases in Gastroenteropancreatic Neuroendocrine Tumor Metastases Compared to the Primary Tumor. Neuroendocrinology 2015, 103, 452459. [CrossRef]

25. Richards-Taylor, S.; Tilley, C.; Jaynes, E.; Hu, H.; Armstrong, T.; Pearce, N.W.; Plant, R.; Cave, J. Clinically Significant Differences in Ki-67 Proliferation Index Between Primary and Metastases in Resected Pancreatic Neuroendocrine Tumors. Pancreas 2017, 46, 1354-1358. [CrossRef]

26. Pusceddu, S.; Barretta, F.; Trama, A.; Botta, L.; Milione, M.; Buzzoni, R.; De Braud, F.; Mazzaferro, V.; Pastorino, U.; Seregni, E.; et al. A classification prognostic score to predict OS in stage IV well-differentiated neuroendocrine tumors. Endocr. Relat. Cancer 2018, 25, 607-618. [CrossRef] [PubMed]

27. Panzuto, F.; Merola, E.; Pavel, M.E.; Rinke, A.; Kump, P.; Partelli, S.; Rinzivillo, M.; Rodriguez-Laval, V.; Pape, U.F.; Lipp, R.; et al. Stage IV Gastro-Entero-Pancreatic Neuroendocrine Neoplasms: A Risk Score to Predict Clinical Outcome. Oncologist 2017, 22, 409-415. [CrossRef]

28. Panzuto, F.; Puscedddu, S.; Faggiano, A.; Rinzivillo, M.; Brighi, N.; Prinzi, N.; Riccardi, F.; Iannicelli, E.; Maggio, I.; Femia, D.; et al. Prognostic impact of tumour burden in stage IV neuroendocrine neoplasia: A comparison between pancreatic and gastrointestinal localizations. Pancreatology 2019, 19, 1067-1073. [CrossRef]

29. Larghi, A.; Capurso, G.; Carnuccio, A.; Ricci, R.; Alfieri, S.; Galasso, D.; Lugli, F.; Bianchi, A.; Panzuto, F.; De Marinis, L.; et al. Ki-67 grading of nonfunctioning pancreatic neuroendocrine tumors on histologic samples obtained by EUS-guided fine-needle tissue acquisition: A prospective study. Gastrointest. Endosc. 2012, 76, 570-577. [CrossRef]

30. Davnall, F.; Yip, C.S.P.; Ljungqvist, G.; Selmi, M.; Ng, F.; Sanghera, B.; Ganeshan, B.; Miles, K.A.; Cook, G.J.R.; Goh, V. Assessment of tumor heterogeneity: An emerging imaging tool for clinical practice? Insights Imaging 2012, 3, 573-589. [CrossRef]

31. Guo, C.; Zhuge, X.; Wang, Z.; Wang, Q.; Sun, K.; Feng, Z.; Chen, X. Textural analysis on contrast-enhanced CT in pancreatic neuroendocrine neoplasms: Association with WHO grade. Abdom. Radiol. 2019, 44, 576-585. [CrossRef]

32. Canellas, R.; Burk, K.S.; Parakh, A.; Sahani, D.V. Prediction of Pancreatic Neuroendocrine Tumor Grade Based on CT Features and Texture Analysis. Am. J. Roentgenol. 2018, 210, 341-346. [CrossRef] [PubMed]

33. Weber, M.; Kessler, L.; Schaarschmidt, B.; Fendler, W.P.; Lahner, H.; Antoch, G.; Umutlu, L.; Herrmann, K.; Rischpler, C. Textural analysis of hybrid DOTATOC-PET/MRI and its association with histological grading in patients with liver metastases from neuroendocrine tumors. Nucl. Med. Commun. 2020, 41, 363-369. [CrossRef] [PubMed]

34. Martini, I.; Polici, M.; Zerunian, M.; Panzuto, F.; Rinzivillo, M.; Landolfi, F.; Magi, L.; Caruso, D.; Eid, M.H.; Annibale, B.; et al. CT texture analysis of liver metastases in PNETs versus NPNETs: Correlation with histopathological findings. Eur. J. Radiol. 2020, 124, 108812. [CrossRef]

35. Lewis, A.; Li, D.; Williams, J.; Singh, G. Pancreatic Neuroendocrine Tumors: State-of-the-Art Diagnosis and Management. Oncology (Williston Park) 2017, 31, e1-e12. [PubMed]

36. Ambrosini, V.; Campana, D.; Bodei, L.; Nanni, C.; Castellucci, P.; Allegri, V.; Montini, G.C.; Tomassetti, P.; Paganelli, G.; Fanti, S. 68Ga-DOTANOC PET/CT Clinical Impact in Patients with Neuroendocrine Tumors. J. Nucl. Med. 2010, 51, 669-673. [CrossRef]

37. Binderup, T.; Knigge, U.; Loft, A.; Mortensen, J.; Pfeifer, A.; Federspiel, B.; Hansen, C.P.; Højgaard, L.; Kjær, A. Functional Imaging of Neuroendocrine Tumors: A Head-to-Head Comparison of Somatostatin Receptor Scintigraphy, 123I-MIBG Scintigraphy, and 18F-FDG PET. J. Nucl. Med. 2010, 51, 704-712. [CrossRef]

38. Rinzivillo, M.; Partelli, S.; Prosperi, D.; Capurso, G.; Pizzichini, P.; Iannicelli, E.; Merola, E.; Muffatti, F.; Scopinaro, F.; Schillaci, O.; et al. Clinical Usefulness of ${ }^{18}$ F-Fluorodeoxyglucose Positron Emission Tomography in the Diagnostic Algorithm of Advanced Entero-Pancreatic Neuroendocrine Neoplasms. Oncologist 2017, 23, 186-192. [CrossRef]

39. Severi, S.; Nanni, O.; Bodei, L.; Sansovini, M.; Ianniello, A.; Nicoletti, S.; Scarpi, E.; Matteucci, F.; Gilardi, L.; Paganelli, G. Role of ${ }^{18}$ FDG PET/CT in patients treated with 177Lu-DOTATATE for advanced differentiated neuroendocrine tumours. Eur. J. Nucl. Med. Mol. Imaging 2013, 40, 881-888. [CrossRef]

40. Sansovini, M.; Severi, S.; Ianniello, A.; Nicolini, S.; Fantini, L.; Mezzenga, E.; Ferroni, F.; Scarpi, E.; Monti, M.; Bongiovanni, A.; et al. Long-term follow-up and role of FDG PET in advanced pancreatic neuroendocrine patients treated with 177Lu-D OTATATE. Eur. J. Nucl. Med. Mol. Imaging 2016, 44, 490-499. [CrossRef]

41. Binderup, T.; Knigge, U.; Johnbeck, C.B.; Loft, A.; Berthelsen, A.K.; Oturai, P.S.; Mortensen, J.; Federspiel, B.; Langer, S.W.; Kjær, A. ${ }^{18}$ F-FDG-PET is superior to WHO grading as prognostic tool in neuroendocrine neoplasms and useful in guiding peptide receptor radionuclide therapy: A prospective 10-year follow-up study of 166 patients. J. Nucl. Med. 2020. [CrossRef]

42. Partelli, S.; Rinzivillo, M.; Maurizi, A.; Panzuto, F.; Salgarello, M.; Polenta, V.; Fave, G.D.; Falconi, M. The Role of Combined ${ }^{68} \mathrm{Ga}-\mathrm{DOT} A N O C$ and ${ }^{18}$ FDG PET/CT in the Management of Patients with Pancreatic Neuroendocrine Tumors. Neuroendocrinology 2014, 100, 293-299. [CrossRef] [PubMed]

43. Kayani, I.; Bomanji, J.B.; Groves, A.; Conway, G.; Gacinovic, S.; Win, T.; Dickson, J.; Caplin, M.; Ell, P.J. Functional imaging of neuroendocrine tumors with combined PET/CT using ${ }^{68}$ Ga-DOTATATE (DOTA-DPhe1,Tyr3-octreotate) and ${ }^{18}$ F-FDG. Cancer 2008, 112, 2447-2455. [CrossRef] [PubMed]

44. Panzuto, F.; Massironi, S.; Partelli, S.; Campana, D.; Rinzivillo, M.; Invernizzi, P.; Andreasi, V.; Lamberti, G.; Falconi, M. Gastroentero-pancreatic neuroendocrine neoplasia: The rules for non-operative management. Surg. Oncol. 2020, 35, 141-148. [CrossRef] [PubMed] 
45. Cives, M.; Pelle', E.; Strosberg, J. Emerging Treatment Options for Gastroenteropancreatic Neuroendocrine Tumors. J. Clin. Med. 2020, 9, 3655. [CrossRef]

46. Gurusamy, K.S.; Ramamoorthy, R.; Sharma, D.; Davidson, B.R. Liver resection versus other treatments for neuroendocrine tumours in patients with resectable liver metastases. Cochrane Database Syst. Rev. 2009, 2009, CD007060. [CrossRef]

47. Gurusamy, K.S.; Pamecha, V.; Sharma, D.; Davidson, B.R. Palliative cytoreductive surgery versus other palliative treatments in patients with unresectable liver metastases from gastro-entero-pancreatic neuroendocrine tumours. Cochrane Database Syst. Rev. 2009, 2009, CD007118. [CrossRef]

48. Rinke, A.; Müller, H.H.; Schade-Brittinger, C.; Klose, K.J.; Barth, P.; Wied, M.; Mayer, C.; Aminossadati, B.; Pape, U.F.; Bläker, M.; et al. PROMID Study Group. Placebo-118 controlled, double-blind, prospective, randomized study on the effect of oc-treotide LAR in the control of tumor growth in patients with metastatic neu-119 roendocrine midgut tumors: A report from the PROMID Study Group. J. Clin. Oncol. 2009, 27, 4656-4663. [CrossRef]

49. Caplin, M.E.; Pavel, M.; Ćwikła, J.B.; Phan, A.T.; Raderer, M.; Sedláčková, E.; Cadiot, G.; Wolin, E.M.; Capdevila, J.; Wall, L.; et al. Lanreotide in Metastatic Enteropancreatic Neuroendocrine Tumors. N. Engl. J. Med. 2014, 371, 224-233. [CrossRef]

50. Caplin, M.E.; Pavel, M.; Ćwikła, J.B.; Phan, A.T.; Raderer, M.; Sedláčková, E.; Cadiot, G.; Wolin, E.M.; Capdevila, J.; Wall, L.; et al. Anti-tumour effects of lanreotide for pancreatic and intestinal neuroendocrine tumours: The CLARINET open-label extension study. Endocr. -Relat. Cancer 2016, 23, 191-199. [CrossRef]

51. Yao, J.; Shah, M.H.; Ito, T.; Bohas, C.L.; Wolin, E.M.; Van Cutsem, E.; Hobday, T.J.; Okusaka, T.; Capdevila, J.; De Vries, E.G.; et al. Everolimus for Advanced Pancreatic Neuroendocrine Tumors. N. Engl. J. Med. 2011, 364, 514-523. [CrossRef]

52. Yao, J.; Fazio, N.; Singh, S.; Buzzoni, R.; Carnaghi, C.; Wolin, E.; Tomasek, J.; Raderer, M.; Lahner, H.; Voi, M.; et al. Everolimus for the treatment of advanced, non-functional neuroendocrine tumours of the lung or gastrointestinal tract (RADIANT-4): A randomised, placebo-controlled, phase 3 study. Lancet 2016, 387, 968-977. [CrossRef]

53. Strosberg, J.; El-Haddad, G.; Wolin, E.; Hendifar, A.; Yao, J.; Chasen, B.; Mittra, E.; Kunz, P.L.; Kulke, M.H.; Jacene, H.; et al. Phase 3 Trial of 177Lu-Dotatate for Midgut Neuroendocrine Tumors. N. Engl. J. Med. 2017, 376, 125-135. [CrossRef] [PubMed] 